\title{
A MEDIAÇÃO PEDAGÓGICA COMO PRÁTICA TRANSFORMADORA: REFLEXÕES SOBRE O LUGAR DO PROFESSOR NA PRODUÇÃO DO CONHECIMENTO SIGNIFICATIVO
}

\section{Pedagogical mediation as a transforming practice: reflections on the teacher's place in the production of significant knowledge}

\author{
Willyan Ramon de Souza Pacheco - UFCG/Brasil
}

\begin{abstract}
RESUMO: O presente artigo objetiva explorar os fatores socioculturais que possibilitam a produção e a aquisição significativa dos conhecimentos escolares. Para isso, tornou-se necessário realizar um levantamento bibliográfico sobre as influências socioculturais no processo de ensino-aprendizagem e a potencialidade da mediação docente na constituição de uma prática intencional e significativa. Nessa perspectiva, adotamos como metodologia de pesquisa para este trabalho a revisão de literatura. $\mathrm{O}$ significado de uma ação pedagógica se constitui a partir dos fatores que estão além das representações de escola e conhecimento. A construção significativa dos conteúdos escolares ocorre no processo de transformação e problematização, isto é, no momento em que o sujeito compreende e adapta o conhecimento sistematizado à sua realidade. Os conhecimentos histórico-culturais que constituem a identidade do educando se configuram em especificidades potencialmente relevantes no processo de abstração e compreensão do conteúdo curricular. Dessa maneira, a mediação docente pode ser compreendida enquanto ação determinante no processo de constituição de uma prática pedagógica compromissada com a aprendizagem significativa dos sujeitos em formação. Essa dimensão transformadora, se constitui a partir da reorientação das práticas adotadas e por meio da ressignificação dos métodos de ensino, possibilitando ao discente compreender efetivamente a relevância da escolarização no âmbito de sua formação integral.
\end{abstract}

Palavras-chave: Aprendizagem significativa. Intencionalidade docente. Mediação pedagógica.

ABSTRACT: This article aims to explore socio-cultural factors that enable production and significant acquisition school knowledge. For this, it became necessary to carry out a bibliographical survey on the socio-cultural influences in teaching-learning process and potentiality of the teacher mediation in the constitution of an intentional and meaningful practice. In this perspective, we have adopted as a research methodology for this work, literature revision. The meaning of a pedagogical action is based on factors that are beyond representations of school and knowledge. The significant construction of the school contents occurs transformation process and questioning, that is, at the moment when the subject understands and adapts the knowledge systematized to his reality. The historical and cultural knowledge that constitute the identity of the educating is configured in specific features potentially relevant abstraction process and understanding of curriculum content. In this way, the teaching mediation can be understood as decisive action process of establishing a committed pedagogical practice with the significant learning of the subject's information. This transforming dimension is based on practices reorientation adopted and through the significance of the teaching methods, enabling the 
student to understand effectively the relevance of schooling in the context their integral formation.

Keywords: Meaningful learning. Teaching intentionality. Pedagogical mediation.

\section{INTRODUÇÃO}

No sistema educacional contemporâneo pouco se tem feito metodologicamente em relação à reorientação da prática docente numa perspectiva humanizadora. Ensinar e aprender ainda tem sido compreendidos numa perspectiva heterogênea, dicotômica e singular. Os processos que conduzem o discente a aquisição dos conhecimentos laborais nem sempre são efetivados de modo coletivo e compartilhado, isto é, o ensino se limita ao docente e a aprendizagem ao discente, sem relacionar as influências e os conhecimentos histórico-culturais trazidos pelos educandos. Em decorrência disso, tornase relevante explorar uma discussão sistemática acerca do processo de ensinoaprendizagem numa dimensão significativa, colaborativa, onde "quem ensina aprende ao ensinar e quem aprende ensina ao aprender" (FREIRE, 2017, p. 25).

Nessa perspectiva, o presente artigo objetiva explorar os fatores socioculturais que possibilitam a produção significativa do conhecimento, permitindo assim a aquisição dos conteúdos e a sua elaboração a partir da ressignificação dos métodos pedagógicos utilizados pelo professor. O processo de ensino-aprendizagem será, portanto, compreendido como a potencialização das habilidades desenvolvidas nos contextos sociais e estimulados à sistematização na educação escolarizada, transformando essa ação mecânica numa prática transformadora.

A aquisição e elaboração do conhecimento se dá no presente, como resultado de todo um passado, individual e cultural, com vistas às estratégias de ação no presente e projetando-se no futuro, desde o futuro imediato até o de mais longo prazo, modificando assim a realidade e incorporando a ela novos fatos (D’AMBRÓSIO, 2005, p. 108).

Nessa acepção, é importante ressaltar a relevância de compreender a aprendizagem como um processo influenciado pelos contextos de cada individuo, ou seja, as relações externas podem contribuir sistematicamente para a apreensão dos conteúdos escolares, desde que exista uma abordagem contextualizada que evidencie no discente a 
A mediação pedagógica como prática transformadora: reflexões sobre o lugar do professor na produção do conhecimento significativo

potencialidade de aprender e ensinar concomitantemente. Para o desenvolvimento dessa abordagem, adotamos os procedimentos metodológicos descritos a seguir.

\section{MATERIAL E MÉTODO}

Para a corporificação dessa discussão, tornou-se necessário realizar um levantamento bibliográfico sobre as influências socioculturais no processo de ensinoaprendizagem e a potencialidade da mediação docente na constituição de uma prática significativa. A partir desse procedimento, tornou-se possível adquirir informações acerca das características formativas do profissional docente e suas contribuições no âmbito da mediação intencional de práticas emancipatórias e significativas. Nessa perspectiva, adotamos como metodologia de pesquisa para este trabalho a revisão de literatura que, na acepção de Gil (2002, p. 44), “é desenvolvida com base em material já elaborado, constituído principalmente de livros e artigos científicos".

Dessa maneira, para que assim pudéssemos materializar o presente estudo, fizemos um levantamento bibliográfico e eletrônico. Utilizando, para isso, obras já produzidas por outros pesquisadores, compreendendo que os textos analisados tornam-se fontes dos temas a serem pesquisados (SEVERINO, 2007).

\section{RESULTADOS E DISCUSSÕES}

A seguinte análise explorou os diversos aspectos que contribuem para a reorientação da prática docente e seu potencial no âmbito do processo de ensinoaprendizagem, configurando a mediação pedagógica intencional enquanto prática determinante na aquisição de conhecimentos significativos. Para isso, fez-se necessário estruturar a discussão em quatro principais categorias: os contextos socioculturais e suas influências na produção do conhecimento; a mediação docente em prol da formação humana; a intencionalidade pedagógica como instrumento de transformação e aprendizagem significativa: alguns apontamentos.

\subsection{Os contextos socioculturais e suas influências na produção do conhecimento}

Compreender que existem fatores externos que são indissociáveis ao processo de ensino-aprendizagem tem sido, nos últimos anos, uma das maiores dificuldades encontradas pelos professores ao lidarem com o fracasso escolar de seus alunos. A falta 
de assimilação, compreensão ou decodificação dos conteúdos abordados, durante o desenvolvimento das aulas, impossibilita o aluno de tirar boas notas e, consequentemente, sentir-se satisfeito com seu desempenho escolar. Essa mensuração negativa da aprendizagem resulta na falta de estímulo e de interesse, por parte do aluno, tanto pela disciplina, quanto pelo ato de aprender.

Proporcionar uma prática capaz de transformar essa realidade é algo distante para a maioria dos profissionais que estão inseridos em salas lotadas com dezenas de alunos de diferentes especificidades. O que podemos evidenciar é que uma mediação pedagógica significativa está mais ligada a predisposição e conhecimento da relevância de adotar uma postura contextualizada, do que mesmo de um suporte governamental ou algo relacionado à estrutura física da instituição. A prática docente poderia, então, estar mais relacionada com seus contextos, adaptando-se a essas particularidades, do que comprometida com a instrução metódica dos conhecimentos técnicos, sem nenhum significado concreto para os alunos.

Quando falamos em ressignificação, estamos direcionando nossa prática à materialização dos conceitos abstratos, o que significa que todos os jargões adotados para ministrar uma aula agora estão relacionados com experiências relevantes que permitiriam a assimilação significativa dos conteúdos, melhor dizendo, a oportunidade de emancipação da condição de sujeito produtor de conhecimento (FREIRE, 2017). Valorizando, efetivamente, os valores socioculturais que são constituídos no âmago da existência de cada educando, qualificando e viabilizando seus próprios saberes.

Por conseguinte, é indispensável que todas essas influências sociais que o aluno traz consigo tornem-se fatores determinantes no processo de elaboração da metodologia utilizada pelo docente em sala. É necessário caracterizarmos essas experiências como conhecimentos populares ou conhecimentos prévios, para que assim compreendamos essa atuação como uma prática significativa que possibilita a aquisição de conhecimentos a longo prazo, desprezando assim uma aprendizagem mecânica e reprodutivista.

Dessa forma, os conhecimentos prévios do educando podem ser visualizados como uma manifestação sociocultural que, constituindo-se a partir de experiências formativas, tornam-se essenciais, intrínsecos e direcionadores à aquisição do saber sistematizado. Ou seja, o discente, a partir dessa concepção, é compreendido como sujeito ativo durante o seu processo de ensino-aprendizagem. No entanto, a capacidade de 
A mediação pedagógica como prática transformadora: reflexões sobre o lugar do professor na produção do conhecimento significativo

levantarmos essas questões e fazê-las enquanto instrumentos condutores para elaboração de metodologias significativas, ainda não foi possível. Como destaca Vitti (1999, p. 32):

Os professores, na maioria dos casos, se preocupam muito mais em cumprir um determinado programa de ensino do que em levantar as idéias prévias dos alunos sobre um determinado assunto, pois julgam ser mais fácil trabalhar com uma série de exercícios padronizados do que estimular comportamentos e atitudes dos alunos que passam por etapas evolutivas.

Nessa perspectiva, o olhar superior daquele que sabe e daquele que está aprendendo é objetivo. Não levar em consideração o que o educando sabe é desqualificálo enquanto sujeito produtor de conhecimento, é também descaracterizar as suas experiências e considerá-las como fragmentos aleatórios que não tem significado algum se não estiverem ligadas ao saber axiomático. Esse comodismo tecnicista de não buscar saber o que o aluno já conhece e o que ele precisa articular com o que ainda não conheceu é o que pode limitar o trabalho docente a uma função instrumental, mecânica, a uma ação desumanizante.

Em decorrência disso, precisamos evidenciar essas influências e compreende-las como ferramenta de ressignificação, possibilitando assim uma reflexão pedagógica que direcione o docente a atuar politicamente nas esferas educacionais a qual está inserido. Essa característica política surge na intencionalidade do professor em selecionar de forma responsável o que deve ou não ser abordado na sala de aula. É esse saber-fazer fazendo que possibilita uma prática humanizadora e significativa para a formação humana do sujeito em escolarização (NÓVOA, 1992).

\subsection{A mediação docente em prol da formação humana}

A função da escola é formar para a cidadania, construir sujeitos tolerantes, respeitosos e que, acima de tudo, estejam capacitados a atuar nas diversas esferas do poder político e econômico, sem nenhuma dificuldade técnica, ou seja, sem qualquer lacuna formativa. Mas para qual cidadania a escola está formando? Que sujeito político está sendo produzido nas salas de aula para atuar com competência e sucesso? Acontece que o ensino técnico e metódico influi diretamente sobre os valores éticos e morais construídos coletivamente pelo contexto social de cada sujeito.

Essa característica metódico-pedagógica pode vir a invisibilizar a formação histórico-cultural daquele sujeito, sobrepondo sua qualificação sistematizada como o 
auge da aquisição dos conhecimentos prontos e acabados, substituindo uma formação integral por competências técnicas reprodutivistas. É nesse aspecto que a educação escolarizada pode humanizar ou desumanizar o sujeito, influenciando diretamente no percurso formativo de sua aprendizagem (SILVA, 1999).

No entanto, essa prática programada que está pensada para corresponder a uma ideologia está progressivamente sendo substituída pelas necessidades de se adaptar as condições onde a escola está inserida. Isto é, o contexto social da escola influencia diretamente no direcionamento do processo de ensino-aprendizagem, ou seja, nas práticas adotadas e desenvolvidas pelo docente. Nesse sentido, a ação pedagógica do professor se compromete com uma formação significativa, relacionando os conteúdos sistemáticos às experiências que constituem sua subjetividade e oportuniza a apreensão de saberes que são mediados através de uma ação transformadora.

Nessa acepção, a mediação pedagógica do professor que atua significativamente nesse processo formativo, torna-se a principal fonte que determina a aquisição de múltiplos conhecimentos. O professor pode estar comprometido com seus objetivos curriculares, cumprindo-os sistematicamente, porém, isso não deve limitá-lo. O que queremos evidenciar é a força transformadora de metodologias que valorizem o conhecimento popular que advém da sociedade, principalmente das classes mais estigmatizadas e frágeis. Só assim a dimensão técnica não será basilar na formação, só assim a atuação docente não será limitada e o conhecimento do educando não será negativado. Nessa perspectiva, La Taille, Oliveira e Dantas (1992, p.33) evidenciam:

A intervenção pedagógica provoca avanços que não ocorreriam espontaneamente. A importância da intervenção deliberada de um indivíduo sobre outros como forma de promover desenvolvimento articula-se com um postulado básico de Vygotsky: a aprendizagem é fundamental para o desenvolvimento desde o nascimento da criança.

Aprender, nessa perspectiva, está estreitamente ligado a condição de existência. Somos, desde cedo, aprendizes influenciados por nossos contextos sociais. Dessa forma, a mediação docente torna-se ferramenta determinante na constituição dos valores permanentes. O professor que está a compreender o valor humano das relações que constituem o sujeito em suas especificidades, permite-se adentrar na singularidade dos alunos, ressignificando sua prática e repensando metodologias inclusivas que articulem o processo de ensino-aprendizagem aos conhecimentos populares. 
A mediação pedagógica como prática transformadora: reflexões sobre o lugar do professor na produção do conhecimento significativo

Porém, para que isso ocorra é fundamental que o professor esteja esclarecido do potencial de sua prática no processo de constituição do sujeito. A capacidade de desenvolver atividades contextualizadas que explanem de forma concreta os conteúdos de sua disciplina e o interliguem, numa ação significativa, aos conhecimentos prévios dos alunos, para que assim obtenha essa assimilação e apreensão coerente, é o principal aspecto formativo do professor humanizador. Profissional que estimula não só o processo de aprendizagem, mas a permanência daquele aluno nos espaços educacionais.

Essa predisposição exige, antes de tudo, uma intencionalidade pedagógica que possibilite o educando a associar todas as informações, debatidas em sala, aos seus contextos sociais. Não se trata apenas de associar os conhecimentos prévios à escola, mas, também, de associar os conhecimentos escolares à sociedade. A construção desse novo modo de conceber o ensino deve estar sustentada em bases sólidas que permitam o professor referencializar sua prática a partir das influências histórico-sociais dos educandos.

\subsection{A intencionalidade pedagógica como instrumento de transformação}

Inicialmente, precisamos compreender que o educador não é um facilitador da aprendizagem, no sentido de que ele poderia oportunizar, de modo simplificado, um nível de desenvolvimento que aconteceria independentemente da escolarização, ou seja, a função do professor não se resume a conduzir os discentes a um processo que aconteceria com ou sem ele. Mas, principalmente, a de evidenciar cotidianamente a potencialidade de uma prática alicerçada no planejamento, no modo de fazer, na intencionalidade de sua prática pedagógica.

Sob o ponto de vista da teoria histórico-cultural, a função do professor é garantir a reprodução, em cada sujeito, das aptidões humanas que são produzidas e desenvolvidas pelo conjunto dos homens e que, sem a transmissão da cultura, não aconteceria (MELLO, 2004). Sendo assim, o significado de uma ação pedagógica se constitui a partir dos fatores que estão além das representações de escola e conhecimento. A construção significativa dos conteúdos se dá no processo de transformação, de problematização, isto é, no momento em que o sujeito compreende e adapta aquele conhecimento a sua realidade. Ferreiro (1986, p. 24) apresenta:

As práticas sociais, assim como as informações sociais não são recebidas passivamente pelas crianças. Quando tentam compreender, 
elas necessariamente transformam o conteúdo recebido. Além do mais, a fim de registrarem a informação, elas a transformam.

Transformar é, nesse sentido, atribuir significado aos conteúdos apresentados pelo docente. Quando compreendemos que as crianças possuem suas especificidades e estas devem ser respeitadas como características de sua identidade, não estamos aceitando a condição de se manter inerte a essa realidade, mas de potencializá-la. O que queremos dizer é que a elucidação desse conhecimento é o passo inicial para produção intencional de metodologias ativas que potencializem as aptidões já estabelecidas, ações essas que serão determinantes nesse processo de transformação.

Nesse aspecto, não é respeitar as especificidades do aluno e determinar sua prática a partir disso, é compreender suas contribuições culturais na produção do conhecimento e fazer disso um instrumento que conduzirá a prática docente a ressignificação dos métodos e, consequentemente, ao crescimento intelectual do discente. Fazer dessa prática associativa um fio condutor à aquisição de conhecimentos mais elaborados é imprescindível, porém, não podemos estagnar nessa característica, é preciso usar essas experiências apenas como ferramenta potencializadora do processo de aprendizagem. Os saberes do educando são elementos que conduzem a prática docente, mas que, pedagogicamente, é utilizado como ponto de partida para o direcionamento aos estudos posteriores.

Assim, a contextualização intencional dos conteúdos torna-se, inicialmente, o principal objetivo do professor que adota para si essa postura emancipatória. É necessário que tudo esteja fundamentado em objetos concretos que podem ser facilmente relacionados com outros. Em alguns momentos a memorização de dados, datas e fórmulas são necessárias, mas o que se deve ter em mente é que o contexto de toda a situação que sustenta aquela teoria deve estar materializada no seguinte questionamenteo: o que é, por que devo aprender e no que me contribuirá?

A memorização é necessária quando o aluno precisa de dados específicos para resolver situações também específicas, é algo particular, porém não menos importante. A atividade de memorização só torna-se mecânica se o discente não compreender o porquê de estar, naquele momento, aprendendo aquilo. Dessa forma é primordial que exista essa historicidade entorno das questões levantadas pelo professor, para que a atividade técnica se ressignifique numa ação emancipatória.

Educação, Psicologia e Interfaces, Volume 2, Número 2, p. 29-42, Maio/Agosto, 2018. 
A mediação pedagógica como prática transformadora: reflexões sobre o lugar do professor na produção do conhecimento significativo

A dimensão intencional, contextualizada e dialógica que o professor adota para si não deve estar limitada apenas ao programa de educação destinado a zonas periféricas, à escolas com rendimento baixo ou a estudantes com necessidades especiais, essa postura pedagógica deve fazer parte da identidade do profissional docente. Dessa forma, a construção de uma aprendizagem significativa deve estar vinculada aos objetivos primordiais de todo o sistema educacional, visando assim uma formação potencializadora que direcione os sujeitos a compreensão real do conhecimento. Porém, quando isso não é considerado, as consequências podem ser irreparáveis, como afirma D’Ambrósio (2005, p. 115):

Na educação, o real é substituído por uma situação que é idealizada para satisfazer os objetivos do dominador. Nada volta ao real ao terminar a experiência educacional. $\mathrm{O}$ aluno tem suas raízes culturais, parte de sua identidade, eliminadas no processo. Essa eliminação produz o excluído.

Nessa perspectiva, a educação se vincula a ideologia reprodutivista que desconsidera qualquer influência social na constituição do ensino ou das políticas que influem sobre sua regulamentação e efetivação metodológica. Assim, no processo de ensino-aprendizagem, quando o conhecimento real não é considerado como instrumento norteador para o potencial, as relações que se estabelecem entre aluno e conteúdo são bloqueadas pelo fator abstração, que impossibilita a compreensão e, consequentemente, a aprendizagem significativa.

\subsection{Aprendizagem significativa: alguns apontamentos}

O mundo real está associado às diversas relações que possibilitam a interação entre os sujeitos de diferentes culturas. Quando essas interações são eliminadas o processo de ensino-aprendizagem, vinculado a uma perspectiva significativa, não tem solidez, portanto, são instrumentos mecanizados com o objetivo de condicionar o sujeito a uma ideologia política. Dessa forma, são as especificidades socioculturais dos sujeitos que tornam possíveis a construção dos conhecimentos, superando a ação de reproduzir, repassar ou ensinar mecanicamente. A partir disso, podemos compreender, conforme Moreira (2012, p. 2), a aprendizagem significativa como

aquela em que ideias expressas simbolicamente interagem de maneira substantiva e não-arbitrária com aquilo que o aprendiz já sabe. Substantiva quer dizer não-literal, não ao pé-da-letra, e não-arbitrária significa que a interação não é com qualquer idéia prévia, mas sim com

Educação, Psicologia e Interfaces, Volume 2, Número 2, p. 29-42, Maio/Agosto, 2018. 
algum conhecimento especificamente relevante já existente na estrutura cognitiva do sujeito que aprende.

Dessa forma, não estamos falando de qualquer aspecto social ou cultural, mas de características relevantes que auxiliem no processo de aprendizagem. Especificamente, de instrumentos subsunçores, ou seja, informações e saberes populares que, através de metodologias ativas, serão capazes de estimular a produção de conhecimentos significativos (AUSUBEL, 2003). A aprendizagem significativa seria então o resultado de uma prática pedagógica direcionada a aquisição intencional de conhecimentos que foram abordados de maneira contextualizada.

Estruturar bases que viabilizem o processo de construção de conhecimento com o aluno, ao invés de para o aluno, deve ser o objetivo principal dos professores que colocam-se como reflexivos e críticos-criativos. Viabilizar seria oportunizar aos discente a possibilidade de expressar-se diante de determinado método de ensino, afinal, para que compreendamos as pluralidades que tanto aqui se fala, é imprescindível que treinemos a nossa capacidade de ouvir, compreender e levar em consideração o que foi colocado.

É importante deixarmos evidente que essa aprendizagem significativa mediada pelo educador nesse processo de construção, está vinculada a todos os fatores políticos e sociais que constituem a estrutura curricular da escola. Este profissional não pode, sozinho, transformar a prática educativa de toda a instituição ao qual está inserido, mas pode contribuir para a superação do modelo tradicional de conceber o conhecimento. Moreira (2012, p. 4) acrescenta:

Aprendizagem significativa não é, como se possa pensar, aquela que o indivíduo nunca esquece. A assimilação obliteradora é uma continuidade natural da aprendizagem significativa, porém não é um esquecimento total. É uma perda de discriminabilidade, de diferenciação de significados, não uma perda de significados. Se o esquecimento for total, como se o indivíduo nunca tivesse aprendido um certo conteúdo é provável que aprendizagem tenha sido mecânica, não significativa.

Nessa perspectiva, compreendemos que é no âmago da profissão docente que as problemáticas que se referem a aprendizagem se constitui. Ora, como saber se o conhecimento teve significado ou se foi uma aprendizagem mecânica que tinha por finalidade apenas a conquista de uma boa nota? O que devemos saber é que a prática educativa deve estar sendo construída e direcionada de forma que possibilite o aluno

Educação, Psicologia e Interfaces, Volume 2, Número 2, p. 29-42, Maio/Agosto, 2018. 
A mediação pedagógica como prática transformadora: reflexões sobre o lugar do professor na produção do conhecimento significativo

acessar aquele conhecimento em momento oportuno. De forma objetiva, o significado é constituído a partir do surgimento de questões contingenciais que são colocadas em um dado momento e que, a partir da inquietação provocada, impulsionam o sujeito a buscar as respostas em suas estruturas cognitivas.

Dessa forma, a aprendizagem significativa não é momentânea, mas também não está inserida em todas as problemáticas que são colocadas no cotidiano. Na verdade, o que torna essa abordagem relevante é a capacidade de lembrarmo-nos de todos os conteúdos apreendidos, em um momento especifico. Não lembraremos de tudo ao mesmo tempo, mas em situações que nos estimulem a recordar e assim a acessar os conhecimentos construídos no âmbito educacional.

Com isso, o professor, que é o mediador de todo esse processo, estará ressignificando sua prática docente visando a produção autônoma do conhecimento e, assim, a elaboração de metodologias que potencializam esse processo. Nesse caso, devemos também estar atentos que não existem instrumentos significativos, mas sujeitos que constroem significados nos instrumentos que o auxiliam nesse processo. Assim, Ausubel (2003, p. 1) elucida:

A aprendizagem significativa não é sinónimo de aprendizagem de material significativo. Em primeiro lugar, o material de aprendizagem apenas é potencialmente significativo. Em segundo, deve existir um mecanismo de aprendizagem significativa.

Dessa forma, o material utilizado nesse processo de contextualização só pode ser potencialmente significativo, não existindo aula significativa, livro significativo ou problema significativo, logo o significado está nas pessoas e não nos materiais usados como veiculadores do processo (MOREIRA, 2012). Assim, são as relações que o docente constrói a partir dos contextos sociais do discente e das metodologias elaboradas, que o processo de construção de uma prática significativa resulta numa aprendizagem também significativa.

Esses instrumentos norteadores impulsionam o processo de construção e possibilitam aos professores a reflexividade pedagógica de reconstruir-se e ressignificarse constantemente, possibilitando assim, uma relação efetiva de escola e sociedade. Reconhecer o conhecimento prévio do aluno e estimulá-lo a potencializar essas habilidades, com respeito e intencionalidade, transforma não apenas a atuação docente, mas a existência dos sujeitos que diariamente são invisibilizados por não estarem 
inseridos numa sociedade institucionalizada.

\section{CONSIDERAÇÕES FINAIS}

A mediação docente se configura numa ação determinante no processo de constituição de uma prática pedagógica compromissada com a aprendizagem significativa dos educandos. Essa dimensão transformadora se constitui a partir da reorientação das práticas adotadas e por meio da ressignificação dos métodos de ensino, possibilitando ao discente compreender significativamente a relevância da escolarização no âmbito de sua formação integral.

As relações que constituem esse processo de escolarização devem estar vinculadas aos aspectos socioculturais dos sujeitos que nele estão inseridos, dessa forma, o processo de ensino aprendizagem não deve ser apenas didático, mas, acessível, concreto, de maneira que seja possível evidenciar os fatores sociais que podem ser relacionados com os conhecimentos sistemáticos. Assim, mesmo que o professor não se converta ao saber dos grupos populares, este não pode arrogantemente impor o seu conhecimento como verdadeiro (FREIRE, 2017).

Essa transformação metodológica oportuniza ao discente a competência de compreender de forma significativa o conteúdo que antes era abstrato, essa ação favorece a aquisição dos conhecimentos necessários a formação cidadã, valoriza as especificidades do aluno, respeita os valores culturais constituídos socialmente, como também qualifica e ressignifica a prática pedagógica do profissional docente. Portanto, a ressignificação do conhecimento popular está vinculada a prática intencional do professor que decide transformar-se para, assim, transformar.

Portanto, a aprendizagem significativa é constituída a partir de uma ação colaborativa que se mobiliza através da intencionalidade pedagógica do professor. Essa dimensão formativa se efetiva durante o desenvolvimento de práticas pedagógicas que oportunizam a ressignificação dos conteúdos abstratos, permitindo, assim, sua internalização a longo prazo. O lugar do professor nesse processo de formação integral é determinante, pois, possibilita o crescimento intelectual e a potencialização das estruturas cognitivas que abrigam os conhecimentos histórico-culturais.

\section{REFERÊNCIAS BIBLIOGRÁFICAS}


A mediação pedagógica como prática transformadora: reflexões sobre o lugar do professor na produção do conhecimento significativo

AUSUBEL, David Paul. Aquisição e retenção de conhecimentos. Lisboa: Plátano Edições Técnicas, 2003. Tradução do original The acquisition and retention of knowledge, 2000.

D’AMBROSIO, Ubiratan. Sociedade, cultura, matemática e seu ensino. Educação e Pesquisa, São Paulo, v. 31, n. 1, p. 99-120, jan./mar. 2005. Disponível em $<$ www.scielo.br/scielo.php?script=sci_arttext\&pid=S151797022005000100008\&lang=pt>. Acesso em: 12 dez. 2017. http://dx.doi.org/10.1590/S1517-970220050001000.

FERREIRO, Emília. Alfabetização em Processos. São Paulo: Cortez, 1986. FREIRE, Paulo. Pedagogia da autonomia: saberes necessários à prática educativa. 55. ed. São Paulo: Paz e Terra, 2017.

GIL, Antônio Carlos. Como elaborar projetos de pesquisa. 4. ed. São Paulo: Atlas, 2002.

LA TAILlE, Yves de.; OLIVEIRA, Marta Kohl de.; DANTAS, Heloysa. Piaget, Vygotsky, Wallon: teorias psicogenéticas em discussão. São Paulo: Summus, 1992.

MELLO, Suely Amaral. A Escola de Vygotsky. In: CARRARA, Kester. (Org.). Introdução à psicologia da educação: seis abordagens. São Paulo: Avercamp, 2004.

MOREIRA, Marco Antonio. O que é afinal Aprendizagem significativa? Aula Inaugural do Programa de Pós-Graduação em Ensino de Ciências Naturais. Instituto de Física, Universidade Federal do Mato Grosso. Cuiabá, MT, 23 de abril de 2010. Aceito para publicação. Qurriculum, La Laguna: Espanha, 2012.

NÓVOA, António. Formação de professores e profissão docente. In: NÓVOA, António. (Coord.). Os professores e a sua formação. Lisboa: Publicações Dom Quixote, 1992.

SEVERINO, Antonio Joaquim. Metodologia do trabalho científico. São Paulo: Cortez, 2007.

SILVA, Ezequiel Theodoro da. Magistério e mediocridade. $4^{\circ}$ ed. São Paulo: Cortez, 1999.

VITTI, Catarina Maria. Matemática com prazer: a partir da história e da geometria. $2^{\circ}$ ed. Piracicaba: Unimep, 1999.

\section{Credenciais do autor}

PACHECO, Willyan Ramon de Souza. Universidade Federal de Campina Grande (UFCG). E-mail: willyanpacheco@ hotmail.com.

Endereço para correspondência: Willyan Ramon de Souza Pacheco, rua Alferes Antônio Francisco - Bairro: Retiro, Uiraúna, Paraíba, 58915-000, Brasil. E-mail: 
willyanpacheco@hotmail.com

Como citar este artigo (Formato ABNT): PACHECO, Willyan Ramon de Souza. A mediação pedagógica como prática transformadora: reflexões sobre o lugar do professor na produção do conhecimento significativo. Educação, Psicologia e Interfaces, vol. 2, n. 2, p. 29-42, 2018. DOI:https://doi.org/10.37444/issn-25945343.v2i2.97

Recebido: 04/02/2018.

Aceito: 20/04/2018. 